\title{
The study of the effectiveness of sound insulation of gypsum wall boards with "Shimast" coating
}

\author{
Semen Totunov*, Michael Ivanov, and Olga Ivanova \\ Bauman M oscow State Technical U niversity, 105005, M oscow, Russia
}

\begin{abstract}
The article presents the experimental studies of sound insulation of a single-layer barrier made of gypsum wall boards with a thin-layer coating. The coating consists of a viscous base and glass airless microgranules. The coating increases the efficiency of reducing air noise. The material is applied as a normal paint by spraying on the surface. The research results have been obtained in an acoustic reverberation chamber designed to study the partition walls effectiveness.
\end{abstract}

\section{Introduction}

Sound insulation is one of the main requirements for human comfort today. Noise requirements in automobiles, production environments, and equipment that create higher sound pressure lead to the need of development more efficient and cost-effective ways to produce sound-absorbing materials [1]. Industrial applications of sound insulation usually include the use of materials such as glass wool, foam, mineral fibers and their composites $[2,3,4]$.

In the past few decades, due to the reinforcement of legal standards on the level of noise affecting people, the problems associated with determining the acoustic characteristics of products have become of particular importance, making them one of the most important criteria for design. It is particularly important to taking these characteristics into account in aerospace products. On the one hand, it is necessary to provide acoustic comfort of the environment, which helps to reduce passenger fatigue, improve the performance of the crew and, as a result, improve the competitive ability of the vehicle. On the other hand, it is extremely important to reduce the weight of structures for aircraft design. However, providing the latter often leads to increased noise and vibration levels.

One of the possible solutions is probably to use multi-layer structures instead of traditional sound-absorbing structures (acoustic panels, sound-absorbing sponges, vinyl sheets), including structures with an energy-absorbing coating (a coating that has high damping properties).

The use of modern materials in construction do not always allow to achieve optimal noise conditions in houses and apartments, or they are time-consuming in installation and expensive, which ultimately leads to an increase in the cost of construction engineering

* Corresponding author: simongf@yandex.ru 
projects. Therefore, the main and promising material in terms of dimensions is the use of liquid-based composite materials [5]. A composite material consists of two or more materials, and its optimal acoustic properties can be developed by selecting its components. The "SHIMAST" coating technology means that it can be applied both to the surface of walls and used as a layer in acoustic panels [6]. The sound wave passing through the layer of such material is partially dispersed in it due to airless granules, and the energy is absorbed by the elastic binding component, which leads to a decrease in intensity and, consequently, a decrease in the noise level behind the partition wall [7]. Materials that use microgranules with air, as well as vacuum granules, have been already becoming available to the customer, although previously such technologies were being used in the military sphere. However, the effectiveness of such materials is poorly predictable and there is a need for full-scale tests in reverberation-type chambers [5].

\section{The measurement methodology}

The goal of study was to determine the influence of thin-layer coating used as thermal insulation for residential accommodations on the sound insulation of partition walls. For this purpose, Knauf drywall panels with a thickness of $9.5 \mathrm{~mm}$ and dimensions of $1.5 \times 1.5 \mathrm{~m}$ with a coating of the brand "SHIMAST", a layer thickness of $3.8 \mathrm{~mm}$ have been studied in the laboratory. This coating is a liquid composition intended for application to walls as a regular paint. During the tests, the plate was fixed between the high and low level (pressure) chambers (HLC and LLC) in accordance with the scheme shown in Fig.1a. The tests have been performed in an acoustic laboratory that meets the requirements of GOST 27296-2012. It includes two adjacent chambers of high and low levels, in the opening between which the test partition wall (Fig. 1), as well as a measuring and control complex with transmitting and receiving systems are installed. Chambers have the following values of area and volume $V_{\Pi}: S_{\Pi}=12,6 \mathrm{~m}^{2}, V_{k}=32 \mathrm{~m}$ (high level), $S_{\Pi}=10 \mathrm{~m}^{2}, V_{k}=25,2 \mathrm{~m}^{3}$ (low level). In accordance with GOST $27296-2012$, they provide a minimum possibility of indirect sound transmission and penetration of side tones.
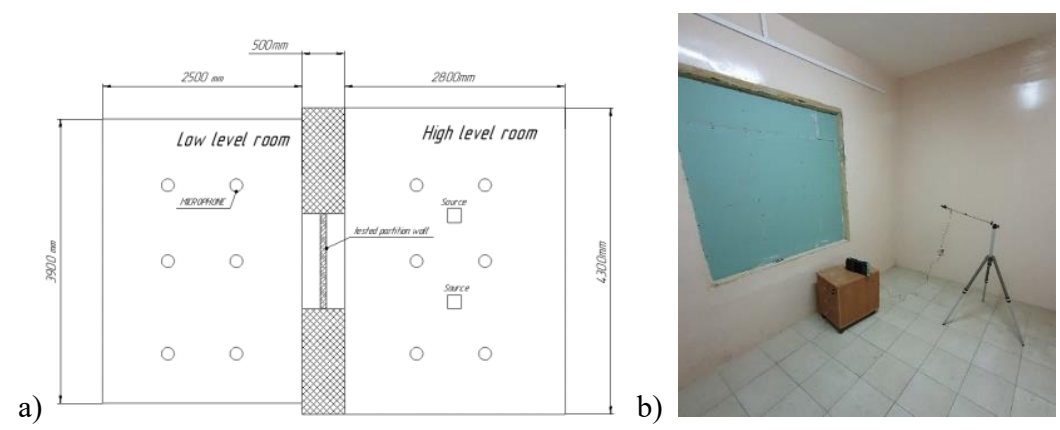

Fig. 1. The study of partition walls in an acoustic chamber: $a$ - the diagram of measurements, $b-$ photo of the tested partition walls during measurement

The measurement system, which was emitting noise, created a diffuse sound field in the room for the measurements. [8,9] The noise sources have been located in two places of the highlevel measuring room.

The measuring microphone in high-and low-level rooms has been installed sequentially at six points (three points for each position of the noise source).

The average sound pressure levels were calculated by the formula: 


$$
L_{m}=10 \cdot \lg \left(\frac{1}{n} \sum_{i=1}^{n} 10^{0.1 * L_{i}}\right)
$$

The equivalent sound absorption area of a low-level room $A_{2}, \mathrm{~m}^{2}$, has been determined by the value of the reverberation time $T_{2}$, by formula:

$$
A_{2}=\frac{0.16 V_{2}}{T_{2}}
$$

where $T_{2}=2,07 \mathrm{~s}$ for the wall board without coating, $T_{2}=1,24 \mathrm{~s}$ for the gypsum board with coating.

Isolation of air noise by enclosing structures $R, \mathrm{~dB}$, has been calculated using the formula:

$$
R=L_{m 1}-L_{m 2}+10 \lg \left(\frac{S}{A_{2}}\right)
$$

where $L_{m 1}$ and $L_{m 2}$ - average sound pressure levels in the third-octave frequency band in high-and low-level rooms, respectively, $\mathrm{dB}$;

$S$ - the area of the tested structure on the side of the low-level room, $\mathrm{m} 2$.

The goal of study was to determine the added sound insulation of "SHIMAST" by the method of sequential measurements of airborne sound insulation of gypsum wall boards without coating and with it. Calculations have been conducted according to GOST 272962012.

\section{The results of measurements}

Figure 2 illustrates the results of physical tests obtained on the basis of the method described above and corresponding to the measurement of sound pressure by microphones located within the volume of the rooms [11].

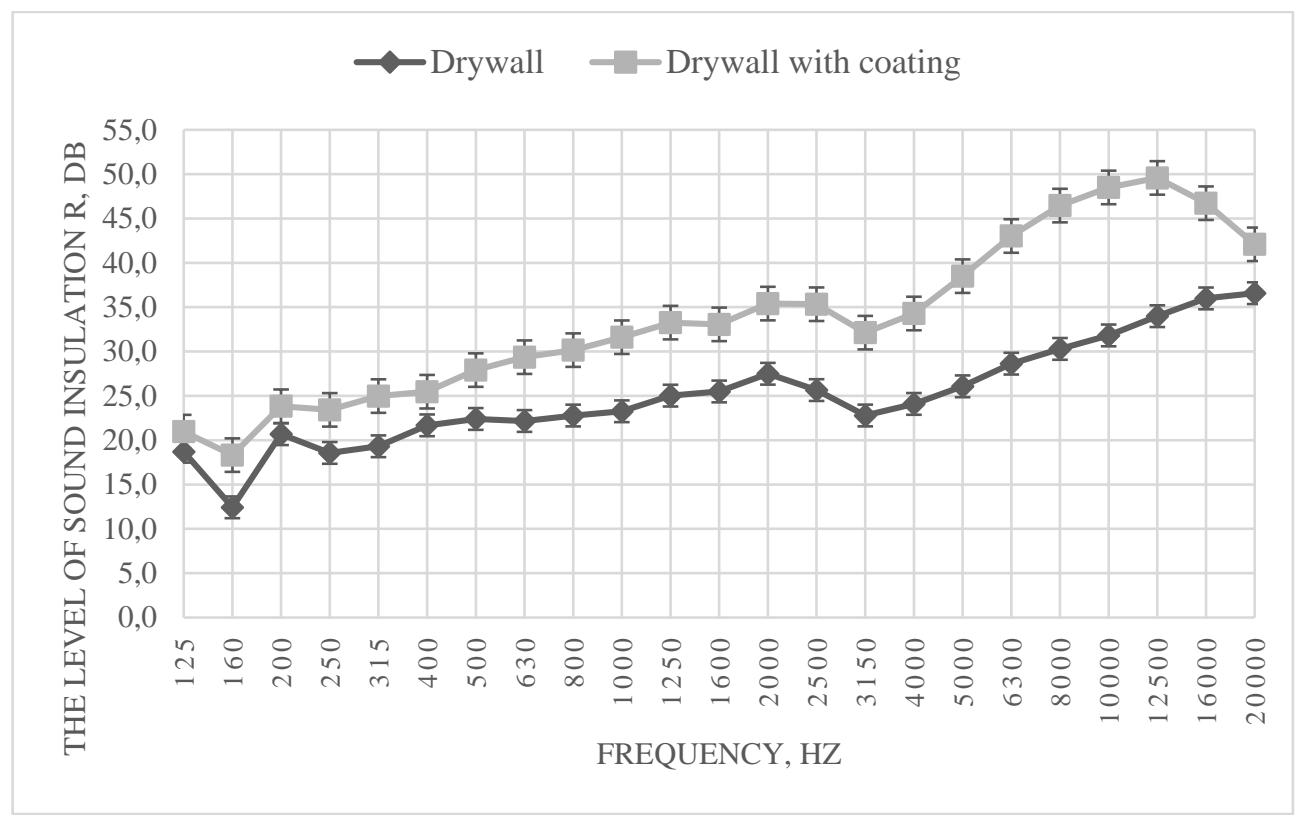

Fig. 2. Comparison of walls sound insulation made of gypsum wall boards without coating and with it 
Based on the obtained values of sound insulation levels, the air noise isolation index has been calculated according to Code $\mathrm{f}$ Regulations 23-103-2003 "The design of sound insulation of enclosing structures of residential and public buildings". The calculation results are shown as graphs in Fig. 3.

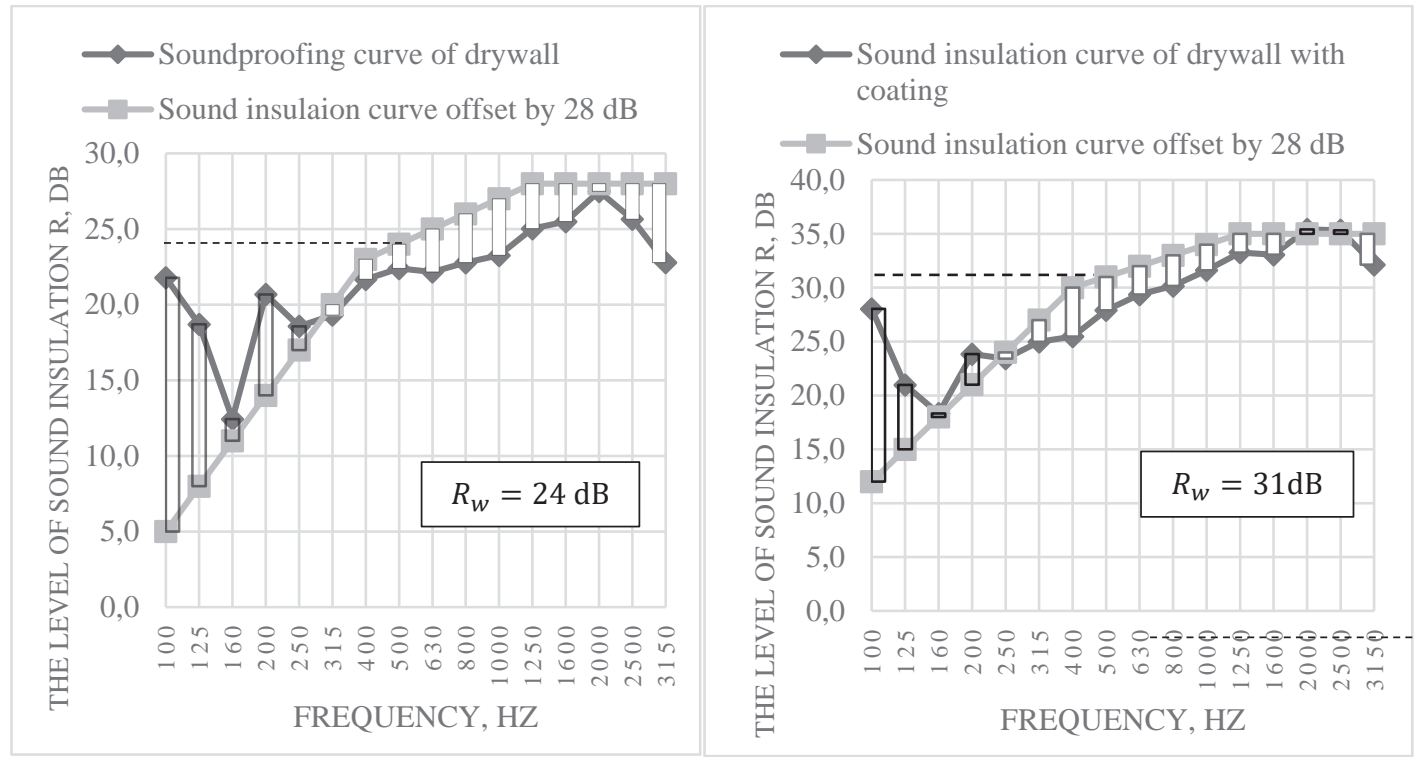

Fig. 3. Comparison of wall sound insulation made of gypsum wall boards without coating and with it

\section{Conclusion}

The obtained results show that the thin-layer coating "SHIMEST" adds $7 \mathrm{~dB}$ of the sound insulation index at a thickness of $3.8 \mathrm{~mm}$. At the same time, the highest efficiency is observed at frequencies of $10-12,5 \mathrm{kHz}$ and is $15.5-17 \mathrm{~dB}$. The main advantage of this paint is the combination of thermal insulation and acoustic properties with a relatively low cost of the material in relation to other coatings on the market [11], many of which do not have supporting documents about their effectiveness. It is difficult to analyze this type of material, which consists of a viscous base of polyurethane, styrene-butadiene rubber and inclusions from airless spheres, theoretically. But this material shows high results in sound insulation. In further research, it is planned to study the interaction of this type of composites with sound waves, as well as the possibility of using them in vibration protection, in more details.

\section{References}

1. V.V. Plotnikov, M.V. Botagovsky. Biosphere compatibility: man, region, technology, 4(12) (2015)

2. H. Ba, Z. Zhan, J. Liu, Z. Ren, M aterials, 12(16), 2509 (2019)

3. I.D. Kraev, E.M. Shuldeshov, M .M. Platonov, G.Y u. Y urkov, A viation materials and technologies journal, 60 (2016)

4. N. I. Ivanov, Main directions and problems of environmental acoustics, Sat. TEZ.

Dokl. XXVII session of RA O, Saint Petersburg, Russia (2014) 
5. D. Y u K orolev,. Painting of exterior fences with new generation materials for energysaving operation of buildings, Scientific Bulletin of the V oronezh State U niversity of A rchitecture and Construction. Proceedings of the interregional scientific and practical conference "High Technologies in Ecology" (N 0. 1, pp. 128-131) (2011)

6. A. Labunsky, B read products, 6, 51-51 (2008)

7. A. A. Strokin, Modelling of noise reduction using reverberation fields of echoic rooms, In A IP Conference Proceedings (V ol. 2195, N o. 1, p. 020072). A IP Publishing L LC, December (2019)

8. A. A . L unkov, A coustical Physics, 65(6), 694-702 (2019)

9. A. Bykov, A. Komkin, V. M oskalenko, Measurements of acoustic flow parameters in the orifice on non-linear regimes, In IOP Conference Series: M aterials Science and Engineering (V ol. 589, N o. 1, p. 012015). IOP Publishing, A ugust (2019)

10. N. G. Kanev, A coustical Physics, 63(6), 731-736 (2017)

11. N. G. Kanev, A coustical Physics, 59(5), 559-564 (2013)

12. Code of Requirements 23-103-2003. The design of sound insulation of enclosing structures of residential and public buildings. 